Saudi Journal of Medicine

Abbreviated Key Title: Saudi J Med ISSN 2518-3389 (Print) |ISSN 2518-3397 (Online) Scholars Middle East Publishers, Dubai, United Arab Emirates

Journal homepage: https://saudijournals.com/sjm

Original Research Article

\title{
Osteoarthritis Knee \& Low Level Laser Therapy-Evidence from Northeast India
}

\author{
Dr. Sharat Agarwal*
}

Associate Professor, Department of Orthopaedics \& Trauma, North Eastern Indira Gandhi Regional Institute of Health \& Medical Sciences (NEIGRIHMS), Shillong, India

DOI: $10.36348 / \mathrm{sjm} .2020 . v 05 i 06.002$

| Received: 05.06.2020 | Accepted: 15.06.2020 | Published: 16.06.2020

*Corresponding Author: Dr. Sharat Agarwal

\section{Abstract}

Although joint pain can be controlled with various modalities which includes the use of acetaminophen, NSAIDs and corticosteroid injections. It has been found that LLLT is an effective non invasive therapy to control inflammation and tissue degeneration and thus to relieve pain with subsequent quality of life improvement in various inflammatory \& painful joint problems. Material \& Methods: A retrospective analysis was done from the data on osteoarthritis knee patients $(n=30)$ with chronic knee pain, treated with low level laser therapy applied at the knee joint line area over medial \& lateral tibiofemoral condyles region. The various parameters like NRS; daily activities, work \& leisure, anxiety \& depression, social interaction (4 components of DALLAS pain questionnaire as found relevant for these patients to assess quality of life) were studied and analysed using appropriate statistical tools. Results: The majority patients were female $(n=17)$ as against males $(n=13)$. The paired t test revealed that there was significant difference in NRS score before and after laser therapy. The paired t test revealed that there was significant difference with positive improvement in daily activities, work \& leisure, Anxiety \& depression and social interaction scores before and after laser therapy. Conclusion: LLLT like Helium Neon (He-Le) laser has the potential to be used with efficacy in patients of chronic knee pain due to osteoarthritis irrespective of age and sex, especially in Kellgren lawrence OA grade 1, 2 \& 3.

Keywords: Osteoarthritis, laser therapy, quality of life, non invasive modalities, musculoskeletal pain.

Copyright @ 2020: This is an open-access article distributed under the terms of the Creative Commons Attribution license which permits unrestricted use, distribution, and reproduction in any medium for non-commercial use (NonCommercial, or CC-BY-NC) provided the original author and source are credited.

\section{INTRODUCTION}

Pain especially the chronic form, is a complex process which deeply effects a person's life, forcing alterations in professional, personal, social and other aspects of everyday activities [1]. Knee pain is the third most frequent cause of chronic pain reported today after low back pain and headache, followed by neck pain, toothache and abdominal pain. Osteoarthritis of knee is the most common type among different causes of knee pain, and a major cause of chronic musculoskeletal pain and mobility, disability in the elderly, and therefore represents a significant burden to the health care provision [2]. Other causes of knee pain include rheumatoid arthritis, gout, joint effusions, systemic lupus erythematosus, psoriatic arthritis etc.

Due to aging in population, the prevalence, disability and associated costs of knee osteoarthritis are expected to steadily increase over next 25 years along with concerns about the increasing obesity-especially in developed countries [3]. Although pain and dysfunction due to osteoarthritis pain troubles $40 \%$ of the adults in the western world, no successful cure for OA has been found till date $[4,5]$. Common methods of treatment for $\mathrm{OA}$ of the knee include joint surgery, medication, electrotherapy, muscle strengthening and external mechanical load reducing devices. None of these treatment options have proven to be consistently successful in clinical practice, although they have all shown variable degree of success [6].

Low level laser therapy (LLLT) in musculoskeletal disorders refers to monochromatic light therapy with lasers which have a mean optical output of larger than $1 \mathrm{~mW}$. LLLT has been used for treatment of $\mathrm{OA}$ for $>30$ years for pain relief and has become increasingly popular non invasive non thermal treatment modality. Unfortunately, though many studies using laser therapy have been conducted over the years pertaining to the improvement of pain relief for various musculoskeletal conditions like rheumatoid arthritis, fibromyalgia, postoperative pain, headache, nervous system diseases, myofascial pain syndrome, chronic neck pain, and low back pain [7-12], the true effectiveness of this therapy is yet to be validated. Hence, laser therapies have yet to receive United States 
Food and Drug Administration (US FDA) approval, except for the treatment of carpal tunnel syndrome.

\section{MATERIAL \& METHODS}

A retrospective analysis was done with the patients diagnosed with osteoarthritis of knee of more than 30 years of age, who were managed with low level laser therapy for knee pain on an outpatient basis (OPD) in the department of orthopaedics \& Trauma at our hospital from January 2018 to May 2019. The therapy used low intensity laser therapy (He-Ne laser of continous mode) of $632.8 \mathrm{~nm}$ wavelength with energy of 3-7 J/cm2 (optimum energy-4 J/cm2) with a penetration depth of $0.8 \mathrm{~cm}$ (using IR 27 ROLAND SERIE, USA machine) to evaluate the efficacy of this mode of treatment for OA knee associated chronic pain. They were graded based on Kellgren-Lawrence grading on radiographs of knee taken in standing anteroposterior, lateral and sunrise views. Patients were evaluated with Numeric pain rating scale (NRS) and modified, the DALLAS Pain Questionnaire, where we studied few components of the pain Questionnaire relevant to the assessment for a patient of chronic knee pain, as to how quality of life was getting affected in patients with knee pain based on four parameters like daily activities, Work \& Leisure activities, Anxiety \& depression due to chronic knee pain \& Social interaction by limiting the functional performance. These patients $(n=30)$ of OA knee (grade 1, $2 \& 3)$ had been subjected to low intensity LASER therapy as one sitting of 30 minutes over the knee joint line per day for five days in a week for 4 consecutive weeks. Pre and 3 months post laser therapy- NRS and modified DALLAS scoring were studied.

\section{RESULTS}

Amongst the patients undertaken in the study, 13 patients were male and there were 17 female patients. Pie diagram shows the characteristics of patients according to sex. Out of 30 patients included in this study, $17(56.6 \%)$ were females and $13(43.4 \%)$ were males (Fig-1). This was obvious it has been found that osteoarthritis of knee is more common in females as compared to males. The response of the patients to treatment was measured in terms of five principal parameters like NRS; daily activities, work \& leisure, anxiety \& depression, social interaction (4 components of DALLAS pain questionnaire as found relevant for these patients to assess quality of life).

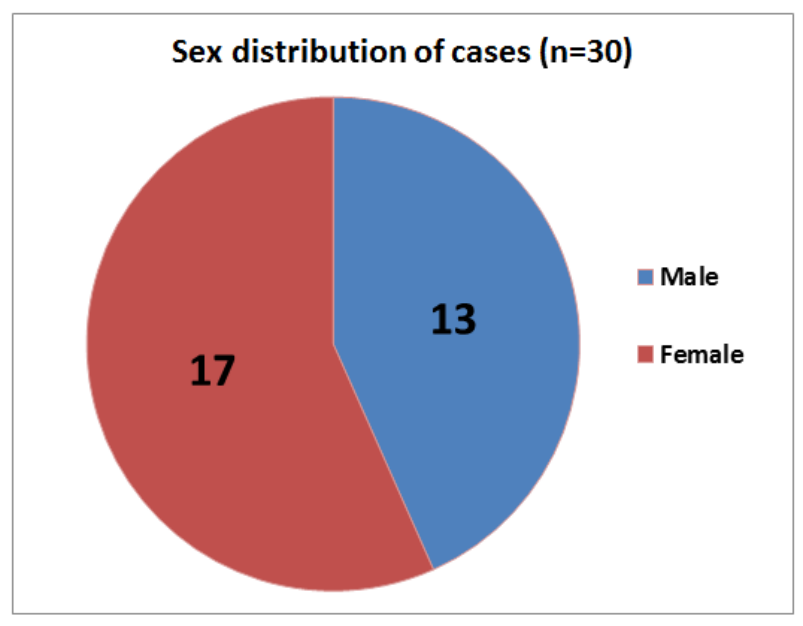

Fig-1: Sex distribution of the cases

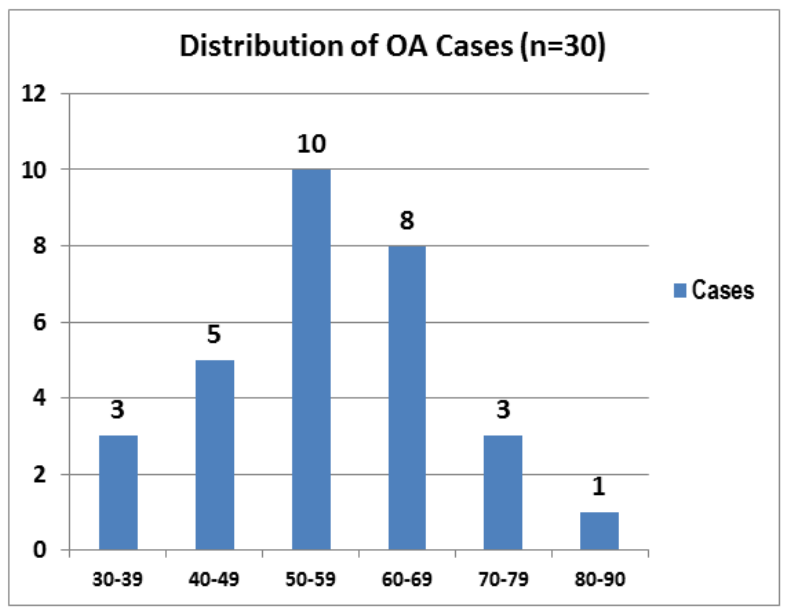

Fig-2: The age wise distribution of the cases in our study was as follows

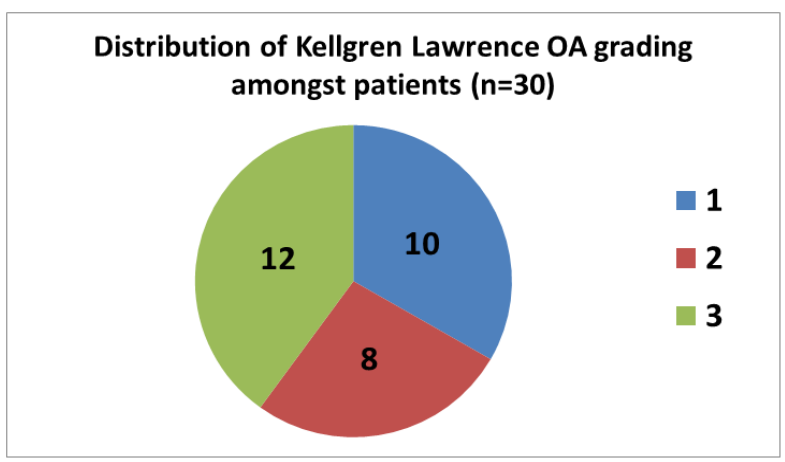

Fig-3: The distribution of cases with respect to KellgrenLawrence grading is as follows 
Table-1: Pre and Post NRS and Modified parameters from DALLAS Pain Score of Participants (N=30)

\begin{tabular}{|c|c|c|c|c|c|c|c|c|c|}
\hline \multirow[t]{2}{*}{ SCORE } & \multicolumn{2}{|c|}{ Pre Score } & \multicolumn{2}{|c|}{ Post Score } & \multirow[t]{2}{*}{ df } & \multirow{2}{*}{$\begin{array}{l}\text { 't' } \\
\text { test }\end{array}$} & \multirow{2}{*}{$\begin{array}{c}\text { 'p' } \\
\text { value }\end{array}$} & \multicolumn{2}{|c|}{$95 \% \mathrm{CI}$} \\
\hline & Mean & S.D & Mean & S.D & & & & Lower & Upper \\
\hline NRS Score & 7.17 & 1.14 & 0.07 & 0.25 & 29 & 35.55 & 0.00 & 6.69 & 7.50 \\
\hline Daily Activities & 33.86 & 14.43 & 1.30 & 2.32 & 29 & 13.37 & 0.00 & 27.58 & 37.54 \\
\hline $\begin{array}{l}\text { Work and Leisure } \\
\text { activities }\end{array}$ & 27.5 & 10.48 & $\begin{array}{l}0 . \\
5\end{array}$ & 1.52 & 29 & 14.01 & 0.00 & 23.05 & 30.94 \\
\hline $\begin{array}{l}\text { Anxiety \& } \\
\text { Depression }\end{array}$ & 33.3 & 12.68 & 0.83 & 2.30 & 29 & 14.72 & 0.00 & 27.98 & 37.01 \\
\hline Social Interaction & 22.66 & 9.16 & 0.33 & 1.26 & 29 & 13.92 & 0.00 & 19.05 & 25.61 \\
\hline
\end{tabular}

Note- $\mathrm{P}$ value $<0.05$ is significant.

The paired t test was applied to find out the significance difference between pre-score and postscore at $\mathrm{p}<0.05$ at level of significance. The mean score of NRS in pre test was $7.17 \pm 1.14$ whereas in post test it was $0.07 \pm 0.25$. The paired t test revealed that there was significant difference in NRS score before and after laser therapy. The pre-test mean score of daily activities was $33.86 \pm 14.43$ whereas in post test it was $1.30 \pm 2.32$ and the calculated t value was 13.37. The mean score of work and leisure activities in pre-test was $27.5 \pm 10.48$ whereas in post-test it was $0.5 \pm 1.52$ and the calculated t value was 14.01 . The pretest mean score of anxiety \& depression was
$33.3 \pm 12.68$ whereas in post test it was $0.83 \pm 2.30$ and the calculated t value was 14.72 .The pre test mean score of social interaction was $22.66 \pm 9.16$ whereas in post test it was $0.33 \pm 1.26$. The paired t test revealed that there was significant difference with positive improvement in daily activities, work \& leisure, Anxiety \& depression and social interaction scores before and after laser therapy.

The differences in five parameters of females and males before treatment were not significant, highlighting equality of pre-treatment conditions of patients across gender (Table-2).

Table-2: A pre-treatment comparison of responses of female $(n=17)$ and male $(n=13)$ patients in their activities. The values are expressed as mean $\pm \mathrm{sd}$

\begin{tabular}{|l|c|c|c|c|}
\hline Parameters & Female & Male & t value & p value \\
\hline NRS & $7.08 \pm 1.32$ & $7.24 \pm 1.03$ & 0.36 & 0.724 \\
\hline Daily Activities & $34.23 \pm 20.03$ & $33.59 \pm 8.74$ & 0.11 & 0.915 \\
\hline Work \& Leisure & $29.23 \pm 10.58$ & $26.18 \pm 10.54$ & 0.79 & 0.440 \\
\hline Anxiety\& Depression & $30.77 \pm 7.87$ & $35.29 \pm 15.36$ & 1.05 & 0.305 \\
\hline Social-Interest & $22.69 \pm 9.92$ & $22.65 \pm 8.86$ & 0.01 & 0.990 \\
\hline
\end{tabular}

Table-3: A post-treatment comparison of responses of female $(n=17)$ and male $(n=13)$ patients in their activities. The values are expressed as mean $\pm \mathrm{sd}$

\begin{tabular}{|l|c|c|c|c|}
\hline Parameters & Female & Male & t value & p value \\
\hline NRS & $0.08 \pm 0.28$ & $0.00 \pm 0.00$ & 1.00 & 0.337 \\
\hline Daily Activities & $1.38 \pm 2.90$ & $1.24 \pm 1.86$ & 0.16 & 0.873 \\
\hline Work \& Leisure Activities & $0.77 \pm 1.88$ & $0.29 \pm 1.21$ & 0.79 & 0.437 \\
\hline Anxiety\& Depression & $0.77 \pm 1.88$ & $0.88 \pm 2.64$ & 0.14 & 0.892 \\
\hline Social-Interest & $0.38 \pm 1.39$ & $0.29 \pm 1.21$ & 0.19 & 0.853 \\
\hline
\end{tabular}

Similarly, the differences in five parameters of females and males after treatment were not significant, highlighting equality of post-treatment conditions of patients across gender (Table-3).

\section{DISCUSSION}

The scientific literature strongly suggests that LLLT modulated pain attenuation takes place through its effect on prostaglandin (PG) synthesis, increase in change of PG type G \& PG type H2 into PG type I2, increase in glucocorticoids urinary excretion, which are beta-endorphin synthesis inhibitor, increase in pain threshold in nerve fibres, increase in serotonin urinary excretion, decrease in histamine and serotonin secretion, decrease in bradykinin synthesis, change in nor epinephrine and epinephrine activity, increase in ATP production, increase in local microcirculation, lymph node circulation enhancement and oedema decline [13-15]. Our study showed that there is significant improvement in pain and quality of life parameters assessed by modified parameters taken from the DALLAS pain scale after the therapy.

Anna Angelova et al., in a randomized clinical study, evaluated the effect of high intensity laser therapy (HILT) in patients with OA. They found it to be effective therapy in comparison to Sham laser [16]. Enas Fawazey Youssef etal in their study concluded that addition of LLLT to exercise training program is more effective in the treatment of patients with knee OA [17]. In a prospective study conducted by Shaik 
raheem Saheb et al., on the relative efficacy of LLLT \& ultrasound in subjects of knee OA, found LLLT to be more effective than ultrasound reducing pain, joint stiffness and stability [18]. Abdullah Raddah Kheshie etal in a prospective RCT, compared LLLT \& HILT in combination with exercises found them to be more effective than exercise alone in knee OA [19]. A prospective study was conducted by Takashi Nakamura et al., on LLLT, found it to be an effective form of treatment in chronic knee pain [20]. N. Marquina etal conducted a RCT utilizing a therapeutic low energy system for pain in knee disorders \& found it to be effective [21]. In a metaanalysis was done by He Jang et al., consisting of 22 trials showed that laser therapy reduces knee joint pain and might be a good alternative to the use of non steroidal anti i-inflammatory drugs (NSAIDs) [22]. Rayegani et al., also compared the pain relief obtained with LLLT vis-a-vis ultrasound (US) found a preference for LLLT in giving pain relief [23]. A prospective study conducted by Fukuda et al., analysed the efficacy of LLLT using Lequesne, VAS (visual Analog Scale), Timed Up \& Go (TUG), goniometry \& dynamometry before and after the treatment. It revealed the efficacy of LLLT in inducing pain relief and functional improvement in patients of knee OA [24]. Pain relieving effect \& improvement of micro circulation as found on thermography was found in a study conducted by Bela Hegedus et al., [25]. Bjordal JM et al., did an analysis including many studies to investigate if low level lase therapy of the joint capsule can reduce pain in chronic joint disorders. They concluded that with the suggested dose range significantly reduces pain and improve health status in chronic joint disorders, but the heterogeneity in patient samples, treatment procedures and trial design calls for cautious interpretation of the results [26].

\section{CONCLUSION}

LLLT has the potential to be used with efficacy in patients of chronic knee pain due to osteoarthritis irrespective of age and sex, especially in Kellgren-lawrence OA grade 1, 2 \& 3. However Helium Neon (He-Ne) laser which has been used here, may not be readily available in all hospitals and has limitation with regard to its use in obese patients due to its limited tissue penetration power. Patients compliance \& motivation can be another potential problem as it requires patient to visit hospital for few weeks for sustained therapy. More randomized controlled studies are required to establish the efficacy of various intensity lasers and their correlation with different grades of knee $\mathrm{OA}$, especially as adjunctive therapy with the availability of platelet rich plasma, hyaluronic acid supplementation, mesenchymal stem cells (MSC), slow acting systemic potentially cartilage regenerating therapies, acupuncture and laser acupuncture currently available in the orthopod's armamentarium. However, LLLT hold a promise as a non invasive therapy, which can be successfully tried in all patients of knee OA.

\section{REFERENCES}

1. Peat, G., McCarney, R., \& Croft, P. (2001). Knee pain and osteoarthritis in older adults: a review of community burden and current use of primary health care. Annals of the rheumatic diseases, 60(2), 91-97.

2. Bosomworth, N. J. (2009). Exercise and knee osteoarthritis: benefit or hazard?. Canadian Family Physician, 55(9), 871-878.

3. Iwamoto, J., Sato, Y., Takeda, T., \& Matsumoto, H. (2011). Effectiveness of exercise for osteoarthritis of the knee: A review of the literature. World journal of orthopedics, 2(5), 37.

4. Lethbridge-Cejku, M., \& Vickerie, J. L. (2003). Summary health statistics for US adults; National Health Survey.

5. Darby, A. J. (1983). Osteoarthritis. Pathology. In: Harris NH, editor. Postgraduate textbook of clinical orthopaedics. Bristol: wright PSG; 389-96

6. Shane, L., \& Grant, D. (1987). Degenerative joint disease-a review of NSAID therapy. On Continuing Practice, 14, 28-34.

7. Ilbuldu, E., Cakmak, A., Disci, R., \& Aydin, R. (2004). Comparison of laser, dry needling, and placebo laser treatments in myofascial pain syndrome. Photomedicine and Laser Therapy, 22(4), 306-311.

8. Dubenko, E. G., Zhuk, A. A., Safronov, B. G., \& Bondarenko, M. I. (1976). Opyt primeneniia izlucheniia lazera maloĭ intensivnosti v klinike nervnykh bolezneǐ (Experience with lasers of low intensity radiation in the treatment of nervous system diseases). Vrach Delo. (10):114-119.

9. Irnich, D., Behrens, N., Gleditsch, J. M., Stör, W., Schreiber, M. A., Schöps, P., ... \& Beyer, A. (2002). Immediate effects of dry needling and acupuncture at distant points in chronic neck pain: results of a randomized, double-blind, shamcontrolled crossover trial. Pain, 99(1-2), 83-89.

10. Pinheiro, A. L., Cavalcanti, E. T., Pinheiro, T. I., Alves, M. J., Miranda, E. R., De Quevedo, A. S., ... \& Rolim, A. B. (1998). Low-level laser therapy is an important tool to treat disorders of the maxillofacial region. Journal of clinical laser medicine \& surgery, 16(4), 223-226.

11. Shaver, S. L., Robinson, N. G., Wright, B. D., Kratz, G. E., \& Johnston, M. S. (2009). A multimodal approach to management of suspected neuropathic pain in a prairie falcon (Falco mexicanus). Journal of Avian Medicine and Surgery, 23(3), 209-213.

12. Iijima, K., Shimoyama, N., Shimoyama, M., Yamamoto, T., Shimizu, T., \& Mizuguchi, T. (1989). Effect of repeated irradiation of low-power $\mathrm{He}-\mathrm{Ne}$ laser in pain relief from postherpetic neuralgia. The Clinical journal of pain, 5(3), 271274.

13. King, C. E., Clelland, J. A., Knowles, C. J., \& Jackson, J. R. (1990). Effect of helium-neon laser 
auriculotherapy on experimental pain threshold. Physical therapy, 70(1), 24-30.

14. Ferreira, D. M., Zângaro, R. A., Villaverde, A. B., Cury, Y., Frigo, L., Picolo, G., ... \& Barbosa, D. G. (2005). Analgesic effect of He-Ne (632.8 nm) low-level laser therapy on acute inflammatory pain. Photomedicine and laser surgery, 23(2), 177-181.

15. Bjordal, J. M., Lopes-Martins, R. A. B., \& Iversen, V. V. (2006). A randomised, placebo controlled trial of low level laser therapy for activated Achilles tendinitis with microdialysis measurement of peritendinous prostaglandin E2 concentrations. British journal of sports medicine, 40(1), 76-80.

16. Angelova, A., \& Ilieva, E. M. (2016). Effectiveness of high intensity laser therapy for reduction of pain in knee osteoarthritis. Pain Research and Management, 2016.

17. Youssef, E. F., Muaidi, Q. I., \& Shanb, A. A. (2016). Effect of laser therapy on chronic osteoarthritis of the knee in older subjects. Journal of lasers in medical sciences, 7(2), 112-119.

18. Saheb ${ }^{1}$, S. R., Gangadhar, C. H., \& Swamy, C. G. (2016). Comparison of the effect of low level laser therapy \& therapeutic ultrasound in Knee osteoarthritis. Asian Journal of Health and Medical Research (AJHMR). 2(3):23-27.

19. Kheshie, A. R., Alayat, M. S. M., \& Ali, M. M. E. (2014). High-intensity versus low-level laser therapy in the treatment of patients with knee osteoarthritis: a randomized controlled trial. Lasers in medical science, 29(4), 1371-1376.

20. Nakamura, T., Ebihara, S., Ohkuni, I., Izukura, H., Harada, T., Ushigome, N., ... \& Kubota, A. (2014).
Low Level Laser Therapy for chronic knee joint pain patients. Laser therapy, 23(4), 273-277.

21. Marquina, N., Dumoulin-White, R., Mandel, A., \& Lilge, L. (2012). Laser therapy applications for osteoarthritis and chronic joint pain-A randomized placebo-controlled clinical trial. Photonics \& Lasers in Medicine, 1(4), 299-307.

22. Jang, H., \& Lee, H. (2012). Meta-analysis of pain relief effects by laser irradiation on joint areas. Photomedicine and laser surgery, 30(8), 405-417.

23. Rayegani, S. M., Raeissadat, S. A., Heidari, S., \& Moradi-Joo, M. (2017). Safety and effectiveness of low-level laser therapy in patients with knee osteoarthritis: a systematic review and metaanalysis. Journal of lasers in medical sciences, 8(Suppl 1), S12-S19.

24. Fukuda, V. O., Fukuda, T. Y., Guimarães, M., Shiwa, S., de Lima, B. D. C., Martins, R. Á. B. L., ... \& Fucs, P. M. M. B. (2011). Short-term efficacy of low-level laser therapy in patients with knee osteoarthritis: a randomized placebo-controlled, double-blind clinical trial. Revista Brasileira de Ortopedia (English Edition), 46(5), 526-533.

25. Hegedüs, B., Viharos, L., Gervain, M., \& Gálfi, M. (2009). The effect of low-level laser in knee osteoarthritis: a double-blind, randomized, placebo-controlled trial. Photomedicine and laser surgery, 27(4), 577-584.

26. Bjordal, J. M., Couppé, C., Chow, R. T., Tunér, J., \& Ljunggren, E. A. (2003). A systematic review of low level laser therapy with location-specific doses for pain from chronic joint disorders. Australian journal of physiotherapy, 49(2), 107-116. 